British Joumal of Haematology, 1976, 34, I59.

\title{
Annotation
}

\section{ADENOSINE DEAMINASE AND IMMUNE FUNCTION}

The past decade has witnessed an explosive growth of basic information related both to the functional organization and physiological characterization of the immune system. The primary immunodeficiencies have provided a persistent stimulus for this exponential growth as exemplified by the considerable excitement attending the description of a deficiency of adenosine deaminase activity (adenosine aminohydrolase EC 3.5.4.4) in a group of patients with the autosomal recessive form of severe combined immunodeficiency (SCID) (Giblett et al, 1972; Knudsen \& Dissing, 1973; Parkman et al, 1975), a disorder of infancy characterized by defects of both cellular and humoral immunity.

Adenosine deaminase (ADA) catalyses the irreversible hydrolytic deamination of adenosine to produce inosine and ammonia. Its role in purine metabolism is illustrated in Fig I which is a simplified representation of the interconversion and catabolism of adenine intermediates as established for the mammalian cell. It can be readily appreciated that adenosine is a common substrate for three potentially competing enzymes, namely adenosine deaminase, adenosine kinase and purine nucleoside phosphorylase. Since adenosine appears to be relatively poor substrate for mammalian purine nucleoside phosphorylase (Paterson, I965; Kim et al, 1968), little, if any, adenosine is catabolized to the base adenine. Adenosine kinase catalyses the synthesis of adenosine monophosphate (AMP) which is either sequentially phosphorylated to ATP or deaminated to inosine monophosphate(IMP). The inosine formed by the dephosphorylation of IMP or by the deamination of adenosine is catabolized to hypoxanthine which is then converted to xanthine and uric acid or converted to IMP, a reaction requiring phosphoribosylpyrophosphate (PRPP) as substrate.

Since the deficiency of ADA activity, which plays a pivotal role in the ultimate fate of intra- or extracellular adenosine (Schrader et al, 1972; Lomax \& Henderson, 1973; Parks \& Brown, 1973), represents the first association of a specific enzyme defect with an inherited disorder of $\mathrm{T}$ and $\mathrm{B}$ cell proliferation and/or differentiation, the elucidation of the nature of this association has been of critical importance. Is the enzyme deficiency and disease state a reflection of genetic deletion or frameshift mutation involving both the locus for ADA and a closely linked locus controlling immune differentiation or does the absent activity exert a primary role in genesis of the disturbance of the immune system in SCID? If the latter is the case, what pathophysiological mechanisms are involved?

Nature of the Association of SCID and ADA Deficiency

An initial suggestion for the association of ADA deficiency and SCID was that the enzyme deficiency reflected a genetic deletion or frameshift mutation fortuitously involving the locus for ADA and a linked locus controlling immune differentiation (Giblett et al, I972). This hypothesis was prompted by observations that indicated possible linkage of the HLA loci with that for ADA (Edwards et al, 1973). However, with the assignment of the locus for

Correspondence: Dr M. B. Van der Weyden, Department of Medicine, Monash University Medical School, Alfred Hospital, Melbourne 318I, Victoria, Australia. 


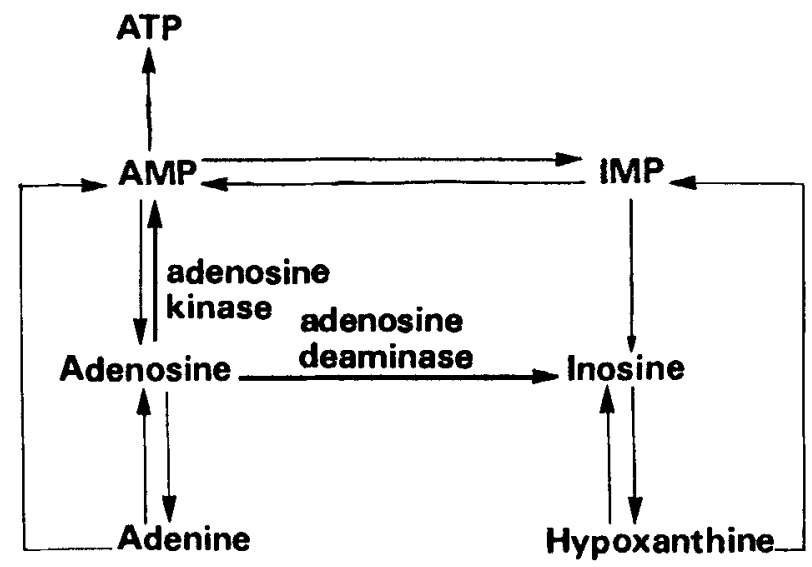

FIG I. Interconversion and catabolism of adenine intermediates. AMP, adenosine monophosphate; ATP, adenosine triphosphate; IMP, inosine monophosphate.

ADA to human chromosome 20 together with evidence for localization of the HLA complex to chromosome 6 (Tischfield et al, I974) this proposition has become untenable. In addition, the demonstration of residual ADA activity in various tissues of patients with ADA deficiency and SCID (Van der Weyden et al, 1974; Chen et al, r975; Hirschhorn et al, 1976) has rendered invalid the proposition that the enzyme deficiency in SCID represented a deletion involving the locus for ADA and an immune response gene unrelated to HLA, since a genetic deletion would be expected to lead to the production of no enzyme protein or a markedly aberrant molecule.

The characterization of the kinetic and physical characteristics of these residual ADA activities (Chen et al, 1975; Hirschorn et al, 1976; Van der Weyden \& Kelley, 1976a) suggest that the deficiency of ADA activity in SCID is the result of a mutation involving the structural locus for ADA. Thus the deficiency of ADA in SCID appears to be a primary genetic defect rather than one resulting from the disease state and it would appear that this deficiency is causally related to the disorder of the immune system in SCID.

The inherited nature of the enzyme deficiency has been adequately documented by (a) the diminished levels of erythrocyte ADA activities transmitted as an autosomal mendelian trait among family members of children with SCID and ADA deficiency (Scott et al, 1974; Parkman et al, I975; Hirschhorn et al, 1975), (b) the demonstration of transmission of a 'null' or 'silent' gene for ADA in two of these families (Chen et al, 1974; Hirschhorn et al, 1975) and (c) the demonstration of ADA activity with altered electrophoretic mobility in fibroblast extracts of obligate heterozygote parents, corresponding to that observed in fibroblast extracts of the homozygotes (Hirschhorn et al, 1976). In this context the occurrence of normal ADA activities in erythrocyte lysates of the parents of one patient with SCID and ADA deficiency (Van der Weyden \& Kelly, I976a) and the restoration in vitro to normal levels of the reduced ADA activity in red cell lysates of obligate heterozygotes and patients with SCID together with the suggestion of a labile inhibitor of enzyme activity in this situation (Trotta et al, 1976) imply that the molecular basis for ADA deficiency in SCID will exhibit considerable heterogeneity. 
Mechanisms whereby the Deficiency of ADA Results in the Expression of SCID

That ADA may play a role in the function of the immune system has been suggested by observations that in the human this activity is highest in tissues with the high lymphoid content such as thymus, spleen or small intestine (Van der Weyden \& Kelley, 1976b). Similarly, the activity of the enzyme is considerably elevated in lymphoblastoid cell lines (Van der Weyden \& Kelley, I976c), in serum and mononuclear cells of patients with infectious mononucleosis (Koehler \& Benz, I962; Van der Weyden, 1976) and in acute lymphoblastic leukaemia or the blastic crisis of chronic myeloid leukaemia (Hutton \& Coleman, 1975; Smyth \& Harrap, 1975). The latter finding is of interest in view of biochemical and immunological evidence for lymphoblastic conversion in chronic myeloid leukaemia (McCaffrey ct al, 1975).

Although an increase in ADA activity has been demonstrated in immunocytes with both the primary or secondary response to antigenic stimulation (Hall, 1963), definitive evidence for the importance of this activity in immunocyte proliferation or function has been the observations that: (a) adenosine or specific inhibitors of ADA activity inhibit lymphocyte and lymphoblast proliferation or promote cytolysis (Green \& Chan, 1973; Fox et al, 1975; Carson \& Seegmiller, 1976; Hovi et al, 1976); (b) exogenous ADA activity stimulates the depressed response of mononuclears from a patient with SCID and ADA deficiency to mitogenic stimulation (Polmar et al, 1975); and (c) adenosine together with specific metabolic inhibitors of ADA activity depresses the function and viability of cellular mediators of both the afferent and efferent limbs of the immune response (Wolberg et al, 1975; Fischer et al, 1976).

Exposure of human fibroblast and lymphoblastoid cells in culture to adenosine at concentrations of ${ }_{10} \mathrm{O}^{-6} \mathrm{M}$ to $\mathrm{IO}^{-5} \mathrm{M}$ results in inhibition of cellular proliferation and a pronounced decrease in cell viability (Green \& Chan, 1973). This toxicity has been postulated to be secondary to an induced state of 'pyrimidine starvation', as a depletion of the intracellular pyrimidine nucleotides occurs and the effect of adenosine can be circumvented by the pyrimidine nucleosides uridine or cytidine. The disturbances in metabolism produced by adenosine, under these circumstances, include a block in the pyrimidine biosynthetic pathway at the level of conversion of orotic acid to uridine monophosphate. This has been postulated to be a reflection of tissue PRPP depletion secondary to inhibition of PRPP synthetase activity (Ishii \& Green, 1973).

These findings have lead to the speculation that the perturbation of the immune system in SCID and ADA deficiency is a result of 'pyrimidine starvation' induced by the accumulation of adenosine in the lymphoid system (Green \& Chan, 1973). That this may not be the case is suggested by: (a) immunodeficiency is not a hallmark of congenital orotic aciduria syndromes secondary to a deficiency of the enzymes involved in the conversion of orotic acid to uridine monophosphate or that involved in PRPP production, namely PRPP synthetase (Smith et al, 1972; Wada et al, r974); (b) megaloblastic haemopoiesis occurs in these situations but is normoblastic in SCID; (c) orotic aciduria does not occur in SCID and ADA deficiency (Schmalsteig et al, 1976); and (d) uridine fails to augment the depressed response of mononuclears of patients with SCID and ADA deficiency to specific mitogens (Parkman et al, 1975; Polmar et al, 1975).

That deamination of adenosine is of importance in immune function is also suggested by the demonstrations that adenosine and specific ADA inhibitors such as erythro-9-(2-hydroxy- 
3-nonyl) adenine or coformycin inhibit the in vitro proliferative response of human mononuclears to specific T or T and B mitogens (Fox et al, 1975; Carson \& Seegmiller, 1976; Hovi et al, 1976). In tandem these two agents exhibit a synergistic effect. Although the precise mechanisms involved remain to be elucidated, interference with PRPP production and a consequent reduction in the rate of purine biosynthesis de novo (Holmes et al, 1973) has been either suggested or implied (Allison et al, x975; Hovi et al, 1976; Carson \& Seegmiller, 1976).

A unifying concept for the effects of ADA deficiency, whether consequent to a mutation or metabolic inhibition, is a disturbance of cAMP metabolism. Firm evidence exists that adenosine and cAMP metabolism are intricately related (Sattin \& Rall, 1970; Shimzu \& Daly, 1970; Mills \& Smith, I97I; Huang \& Daly, I974; Blume \& Foster, 1975) and increased cAMP levels have been demonstrated in fibroblast extracts of a patients with SCID and ADA deficiency (Goldblum et al, 1976). In addition, cAMP has a negative effect on both immunocyte proliferation or function (Hirschhorn et al, 1970; Millis et al, 1974; Bourne et al, 1974) and PRPP synthetase activity (Chambers et al, 1974). The localization of a specific adenosine receptor (Huang \& Daly, 1974) modulating adenylate cyclase activity to plasma membranes together with evidence for localization of ADA activity to the same cellular compartment (Trams \& Lauter, 1975; Li \& Hochstadt, 1976; Van der Weyden \& Kelley, 1976b) are all compatible with this hypothesis.

Wolberg et al (1975) have shown that the in vitro destruction of murine ascites leukaemia cells by specifically sensitized lymphocytes can be inhibited by adenosine. This phenomenon is potentiated by metabolic inhibitors of ADA and is accompanied by an increase in cAMP levels in the effector cells. In the light of these findings it has been suggested that the absence of ADA activity in lymphoid tissue will render these cells particularly sensitive to inhibition of an effector mechanism mediated through adenosine-cAMP metabolism. Complementing these findings has been the demonstration of a role for ADA in monocytemacrophage maturation in which a two- to nine-fold increase in ADA activity occurs (Fischer et al, 1976). Although the addition of varying concentrations of adenosine alone fails to affect this maturation, adenosine will produce varying degrees of cytolysis in the presence of specific inhibitors of ADA, an effect which cannot be circumvented by simultaneous incubation with uridine. Similarly incubation of monocytes with cAMP blunts the monocyte macrophage maturation process.

\section{Acquired ADA Deficiency}

Documentation of the importance of ADA in acquired immune disturbances is in its infancy. Already, however, reduced ADA activity has been demonstrated in lymphocytes in chronic lymphatic leukaemia (CLL) (Hutton \& Coleman, 1975; Huang et al, i975; Tung et al, 1976) and in lymphocytes of parents and children with acute lymphocytic leukaemia in remission (Zimmer et al, I975). While reduced ADA activity in CLL is a direct reflection of the predominance of $B$ cells, which have low activity, it is not clear whether the low activity is a primary event or the result of the longevity of these cells. The finding of increased adenylate cyclase activity in CLL lymphocytes (Mendelsohn et al, 1975) is in keeping with the adenosine - cAMP hypothesis proposed above.

In conclusion, although it has been adequately established that $\mathrm{ADA}$ is of importance in the 
function of the immune system, the unravelling of its precise role or in fact that of purine biosynthesis in toto promises to be a most exciting chapter in the detailing of purine metabolism in man. That this will be a promising avenue of investigation is highlighted by the recent finding of purine nucleoside phosphorylase deficiency in a child with marked impairment of $\mathrm{T}$ cell immunity (Giblett $e t$ al, 1975 ). In this situation, a functional ADA deficiency secondary to inhibition of its activity by the accumulation of inosine has been proposed.

\section{ACKNOWLEDGMENTS}

The authors acknowledge financial support from grants AM 1697I from the National Institute of Health and by grants from the National Foundation and the National Research Council of Australia.

Department of Medicine, Martin B. Van Der Weyden Monash University Medical School, Alfred Hospital, Melbourne, Victoria, Australia

Department of Internal Medicine, William N. Kelley University of Michigan Medical School, University Hospital, Ann Arbor, Michigan, U.S.A.

\section{REFERENCES}

Allison, A.C., Hovi, T., Watts, R.W. E. \& Webster, A.D.B. (1975) Immunological observations on patients with Lesch-Nyhan syndrome and on the role of de novo purine synthesis in lymphocyte transformation. Lancet, $\mathbf{i i}$, I 779.

Blume, A.J. \& Foster, C.J. (I975) Mouse neuroblastoma adenylate cyclase. Adenosine and adenosine analogues as potent effectors of adenylate cyclase activity. Journal of Biological Chemistry, 250, 5003 .

Bourne, H.R., Lichenstan, L.M., Melmon, K.L., Henney, C.S. \& Weinstern, Y. (1974) Modulation of inflammation and immunity by cyclic AMP. Science, I84, I9.

Carson, D.A. \& Seegmiller, J.E. (1976) Effect of adenosine deaminase inhibition upon human lymphocyte blastogenesis. Journal of Clinical Investigation, $57,274$.

Chambers, D.A., Martin, D.W., Jr \& Weinstein, Y. (1974) The effect of cyclic nucleotides on purine biosynthesis and the induction of PRPP synthetase during lymphocyte activation. Cell, 3, 375.

Chen, S.-H., ScotT, C.R. \& Giblett, E.R. (1974)
Adenosine deaminase: demonstration of a silent gene associated with combined immunodeficiency disease. American Journal of Human Genetics, 26, I03.

Chen, S.-H., ScotT, C.R. \& Swedrerg, K.R. (I975) Heterogeneity for adenosine deaminase deficiency: expression of the enzyme in cultured fibroblasts and amniotic fluid cells. American Joumal of Human Genetics, 27, 46.

Edwards, J.H., Allen, F.H., GlenN, K.P., LAMm, L.U. \& RoBson, E.B. (1973) The linkage relationship of HL-A. Histocompatability Testing 1972 (ed. by J. Dausset and J. Colombani), p 745. Munskgaard, Copenhagen.

FischrR, D., VAN DER Whyden, M.B., SNYderman, R. \& KELLEY, W.N. (1976) A role for adenosine deaminase in human monocyte maturation. Joumal of Clinical Investigation, (in press).

Fox, I.H., Keystone, E.C., Gladman, D.D., MoORE, M. \& CANE, D. (I975) Inhibition of mitogen mediated lymphocyte blastogenesis by adenosine. Immunological Communications, 4, 419.

Gibletr, E.R., Anderson, J.E., Cohen, F., Pollara, B. \& MruWussan, H.J. (1972) Adenosine deaminase 
deficiency in two patients with severely impaired cellular immunity. Lancet, ii, 1067.

GIBLETT, E.R., AMMAN, A.J., WARA, D.W., SANDMAN, R. \& DiAmond, L.K. (1975) Nucleoside-phosphorylase deficiency in a child with severely defective T-cell immunity and normal B-cell immunity. Lancet, i, roro.

Goldblum, R.M., Schmalstieg, F.C., Nelson, A., Monakan, T. \& MiLs, G. (1976) Elevated levels of lymphocyte adenine nucleotides in adenosine deaminase deficiency. (Abstract). Clinical Research, 24, 68A.

Grenn, H. \& Chan, T.-S. (1973) Pyrimidine starvation induced by adenosine in fibroblasts and lymphoid cells: role of adenosine deaminase. Science, 182, 836 .

Hall, J.G. (1963) Adenosine deaminase in lymphoid cells during antibody production. Australian Joumal of Experimental Biology, 4I, 93.

Hirschiorn, R., Grossman, J. \& Whissman, G. (1970) Effect of cyclic $3^{\prime}, 5^{\prime}$-adenosine monophosphate and theophylline on lymphocyte transformation. Proceedings of the Society for Experimental Biology and Medicine, 133, ${ }_{3} 61$.

HirschHorn, R., Beratis, N., Rosen, F.S., Parkman, R., StrRn, R. \& Polmar, S. (1975) Adenosine deaminase deficiency in a child diagnosed prenatally. Lancet, i, 73.

HirschHorn, R., Beratts, N. \& Rosen, F.S. (1976) Characterization of residual enzyme activity in fibroblasts from patients with adenosine deaminase deficiency and combined immunodeficiency: evidence for a mutant enzyme. Proceedings of the National Acadenty of Sciences of the United States of America, 73, 104.

Holmes, E.W., Wynganden, J.B. \& Kelley, W.N. (1973) Human glutamine phosphoribosylpyrophosphate amidotransferase. Two molecular forms interconvertable by purine ribonucleotides and phosphoribosylpyrophosphate. Joumal of Biological Chemistry, 248, 6035.

Hovi, T., Smrth, J.F., Allison, A.C. \& Williams, S.C. (1976) Role of adenosine deaminase in lymphocyte proliferation. Clinical and Experimental Immuno$\log \gamma, 23,395$.

Huang, M. \& Daly, J.W. (1974) Adenosine-elicited accumulation of cyclic adenosine monophosphate in brain slices: potentiation of agents which inhibit the uptake of adenosine. Life Stiences, 14, 489.

Huang, A.T., Engalbrecht, H.L., Logue, G.L. \& SANAL, O. (1975) A biochemical difference in human lymphocyte subpopulations separated by complement-mediated rosette method. (Abstract). Blood, 46, 1035 .

HutTon, J.J. \& Coleman, M.S. (1975) Activity of adenosine deaminase in lymphoproliferative diseases. (Abstract). Clinical Research, 23, 425A.
IsHII, K. \& Grern, H. (1973) Lethality of adenosine for cultured mammalian cells by interference with pyrimidine biosynthesis. Joumal of Cell Science, 13, 429.

KIM, B.K., ChA, S. \& Parks, R.E., JR (1968) Purine nucleoside phosphorylase from human erythrocytes. I. Purification and properties. Joumal of Biological Chemistry, 243, 1763 .

KNUdSEn, B.B. \& Dissing, J. (1973) Adenosine deaminase deficiency in a child with severe combined immunodeficiency. Clinical Genetics, 4, 344 .

KonfrirR, L.M. \& BBNZ, E.J. (rg62) Serum adenosine deaminase: methodology and clinical applications. Clinical Chemistry, 8, 133 .

Li, C.-C. \& HochstadT, J. (1976) Transport mechanisms in isolated plasma membranes. Journal of Biological Chemistry, 25I, II75.

Lomax, C.A. \& Henderson, J.F. (1973) Adenosine formation and metabolism during adenosine triphosphate catabolism in Ehrlich ascites tumor cells. Cancer Research, 33, 2825.

MCCaffrey, R., Greaves, M., Harrison, T.A., Revirzs, T., Beard, M. \& Baltimore, D. (I975) Biochemical and immunological evidence for lymphoblastic conversion in chronic myelogenous leukemia. (Abstract). Blood, 46, I043.

Mrndelsohn, J., Parmer, R.J. \& Multer, M.M. (1975) Altered cyclic AMP metabolism in chronic lymphocytic leukemia lymphocytes. (Abstract). Blood, 46, 1044.

Milus, A.J.T., Forrest, G.A. \& Prous, D.A. (I974) Cyclic AMP dependent regulation of mitosis in human lymphoid cells. Experimental Cell Research, 83, 335 .

MiLs, D.C.B. \& SMrTh, J.B. (197I) The influence of platelet aggregation of drugs that affect the accumulation of adenosine $3^{\prime}, 5^{\prime}$ cyclic monophosphate in platelets. Biochemical Joumal, $\mathbf{1 2 1}, \mathbf{1 8 5}$.

Parkman, R., Gelrand, E.W., Rosen, F.W., SANDerson, A. \& Hrrschrorn, R. (1975) Severe combined immunodeficiency and adenosine deaminase deficiency. New England Journal of Medicine, 292, 975 .

PARKS, R.E., JR \& BRown, P.R. (I973) Incorporation of nucleosides into the nucleotide pools of human erythrocytes. Adenosine and its analogs. Biochemistry, 12, 3294.

PatBrson, A.R.P. (1965) The biosynthesis of extracellular ribonucleosides by ascites tumor cells in vitro. Canadian Journal of Biochemistry, 43, 257.

Polmar, S.H., Wetzlar, E.M., StrRn, R.C. \& HIRSCHHORN, R. (1975) Restoration of in vitro lymphocyte responses with exogenous adenosine deaminase in a patient with severe combined immunodeficiency. Lancet, $\mathbf{i}, 743$.

SatTIN, A.\& RaLL, T.W. (I970) The effect of adenosine and adenine nucleotides on the cyclic adenosine 
$3^{\prime}, 5^{\prime}$ phosphate content of guinea pig cerebral cortex slices. Molecular Pharmacology, 6, I3.

Schmalsteig, F.C., Mills, G. \& Goldblum, R.M. (1976) Purine and pyrimidine metabolism in adenosine deaminase deficiency. (Abstract). Clinical Research, 24, 69A.

SCHRADER, J., BERNE, R.M. \& RUBIo, R. (I972) Uptake and metabolism of adenosine by human erythrocyte ghosts. American Joumal of Physiology, 223, I 59 .

Scott, C.R., Chen, S.-H. \& Grblett, E.R. (1974) Detection of the carrier state in combined immunodeficiency associated with adenosine deaminase deficiency. Journal of Clinical Investigation, 53, II94.

Shimizu, H. \& Daly, J. (1970) Formation of cyclic adenosine $3^{\prime}, 5^{\prime}$ monophosphate from adenosine in brain slices. Biochimica et Biophysica Acta, 222, 465.

SMITH, L.H., JR, Huguley, C.M., Jr \& Bain, J.A. (1972) Hereditary orotic aciduria. Metabolic Basis of Inherited Diseases (ed. by J. B. Stanbury, J. B. Wyngaarden and D. S. Fredrickson), p roo3. McGraw-Hill, New York.

SMYTH, J.F. \& HARRAP, K.R. (1975) Adenosine deaminase activity in leukaemia. British Journal of Cancer, 3I, 544 .

Tischfield, J.A., Creagan, R.P., Nichols, E.A. \& RudDIB, F.H. (1974) Assignment of a gene for adenosine deaminase to human chromosome 20. Human Heredity, 24, I.

Trams, E.G. \& LaUTER, C.J. (1975) Adenosine deaminase in cultured brain cells. Biochemical Joumal, 152, 68I.

TrotTA, P.P., SMITHWICK, E.M. \& Balis, M.E. (1976) A normal level of adenosine deaminase activity in red cell lysates of carriers and patients with severe combined immunodeficiency. Proceedings of the
National Academy of Sciences of the United States of America, 73, 104.

Tung, R., Silbrr, R., Quagliata, F., Conkiyn, M., GotTbSMAN, J. \& HIRSCHHORN, R. (1976) Adenosine deaminase activity in chronic lymphocytic leukemia. Journal of Clinical Investigation, 57, 756.

VAN DER WBYDEN, M.B. (I976) Unpublished observations.

VAN DER WeYdBn, M.B., BuckLBY, R.H. \& KrLlBy, W.N. (1974) Molecular form of adenosine deaminase in severe combined immunodeficiency. Biochemical and Biophysical Research Communications, 57, 590.

VAN DHR WeYden, M.B. \& KhIlay, W.N. (1976a) Catalytic and physical characteristics of residual adenosine deaminase activity in severe combined immunodeficiency. (In preparation).

VAN DER WEYDEN, M.B. \& KeLLEY, W.N. (1976b) Human adenosine deaminase: distribution and properties. Journal of Biological Chemistry (in press).

VAN DRR WEYDEN, M.B. \& KeILEY, W.N. (1976c) Unpublished observations.

WADA, Y., Nishimura, Y., TANABU, M., Yoshimura, Y., InNuma, K., Yoshma, T. \& Arakawa, T. (1974) Hypouricemic, mentally retarded infant with a defect of s-phosphoribosyl-I-pyrophosphate synthetase of erythrocytes. Tohoku Journal of Experimental Medicine, Ir3, 149.

Wolberg, G., Zimmarman, T.P., Hinmstra, K., Winston, M. \& ChU, L.-C. (I975) Adenosine inhibition of lymphocyte-mediated cytolysis: a possible role for cyclic adenosine monophosphate. Science, 187, 957.

Zimmer, J., Khalipa, A.S. \& Lightbody, J.J. (1975) Decreased lymphocyte adenosine deaminase activity in acute lymphocytic leukemic children and their parents. Cancer Research, 35, 68. 